Ann. Geophys. Discuss., https://doi.org/10.5194/angeo-2018-76

\title{
Capturing the signature of heavy rainfall events using the 2-d-/4-d water vapour information derived from GNSS measurement \\ in Hong Kong
}

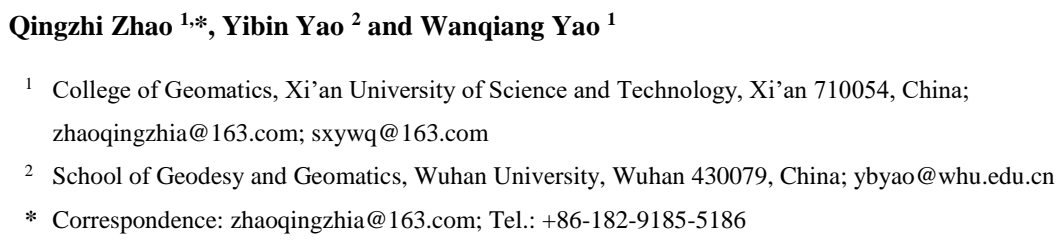

Abstract: Apart from the well-known applications like positioning, navigation and timing (PNT), Global Navigation Satellite System (GNSS) has manifested its ability in many other areas that are vital to society largely. With the dense setting of the regional continuously operating reference station (CORS) networks, monitoring the variations in atmospheric water vapour using a GNSS technique has become the focus in the field of GNSS meteorology. Most previous studies mainly concentrate on the analysis of relationship between the two-dimensional (2-d) Precipitable Water Vapour (PWV) and rainfall while the four-dimensional (4-d) variations of atmospheric water vapour derived from the GNSS tomographic technique during rainfall events are rarely discussed. This becomes the focus of this work, which investigates the emerging field of GNSS technology for monitoring changes in atmospheric water vapour during rainfall, especially in the vertical direction. This paper includes an analysis of both 2-d, and 4-d, precipitable water vapour profiles. A period with heavy rainfall events in this study was selected to capture the signature of atmospheric water vapour variation using the ground-based GNSS tomographic technique. GNSS observations from the CORS network of Hong Kong were used. Analysed results of the 2-d PWV/4-d water vapour profiles change during the arrival, occurrence, and depression of heavy rainfall show that: (i) the PWV time series shows an increasing trend before the arrival of heavy rainfall and decreases to its average value after the depression of rainfall; (ii) rainfall leads to an anomalous variation in relative humidity and temperature while their trends are totally opposite and show daily periodicity for periods without rain (this is highly correlated with the changes in solar radiation); (iii) atmospheric water vapour presents unstable conditions with intense vertical 
Ann. Geophys. Discuss., https://doi.org/10.5194/angeo-2018-76

Manuscript under review for journal Ann. Geophys.

Discussion started: 23 July 2018

(c) Author(s) 2018. CC BY 4.0 License.

convective motion and hydrometeors are formed before the arrival of rainfall while returning to relatively stable conditions during heavy rainfall. This study indicates the potential for using GNSS-derived 2-d PWV and 4-d profiles to monitor spatio-temporal variations in atmospheric water vapour during rainfall, which provides a better understanding of the mechanism of convection and rainfall induced by the extreme weather events.

Keywords: GNSS; PWV; water vapor profiles; extreme weather events

\section{Introduction}

Precipitable water vapour (PWV), which refers to the total content of integrated water vapour density along the zenith direction, is a significant component reflecting the short-term atmospheric water vapour variations used in severe weather detection as well as in long-term climate studies (Bai, 2004; Liu et al., 2013); however, it is difficult to obtain a satisfactory spatio-temporal resolution of atmospheric water vapour due to the limitation of both the number of traditional sounding stations and the observation times (Brenot et al., 2013; Zhang et al., 2015). For the past 20 years, the ability to estimate water vapour contents with an accuracy of 1 to $2 \mathrm{~mm}$ has been proved using the Global Navigation Satellite System (GNSS), which generally formed a new field of study in GNSS Meteorology (Bevis et al., 1992). Therefore, the variation of atmospheric water vapour with high accuracy, as well as the high spatio-temporal resolution can be obtained using the hyper-dense GNSS networks (with receivers only a few kilometres apart).

$\mathrm{PWV}$, at high spatio-temporal resolution is an indicator for monitoring the water vapour responses to severe weather events (Zhang et al., 2015; Yao et al., 2017; Zhao et al., 2018a, 2018b). It has been used for operational meteorology in some areas such as Japan (JMA, 2013), the UK (Bennitt and Jupp, 2012), France (Guerova et al., 2016), and Italy (Barindelli et al., 2018). In those areas, the zenith total delays (ZTD) or PWV estimated from ground-based GNSS measurements are generally assimilated into numerical weather prediction (NWP) models (De Haan 2013; Saito et al., 2017). In addition, ZTD or PWV is also used for the early warning and forecasting of severe precipitation, which has been investigated in areas of Greater Lisbon in Portugal as well as Zhejiang Province in China (Benevides et al., 2015; Yao et al., 2018; Zhao et al., 2018a, 2018b). These applications have verified the ability of GNSS as used in meteorology, but those cases are mainly focussed on two-dimensional (2-d) PWV which cannot reflect the specific vertical 
Ann. Geophys. Discuss., https://doi.org/10.5194/angeo-2018-76

Manuscript under review for journal Ann. Geophys.

Discussion started: 23 July 2018

(c) Author(s) 2018. CC BY 4.0 License.

61 variations in atmospheric water vapour.

62 Although GNSS tropospheric tomography has been proposed (Flores et al., 2000), and can be used to obtain four-dimensional (4-d) water vapour variations, the development of this technique has mainly focussed on improvement of theoretical and model aspects while its application is rarely discussed. For example, the reliability of GNSS tomography was validated using radiosonde data by Seko et al. (2000) and Troller et al. $(2002,2006)$. The joint reconstruction of atmospheric water vapour was also investigated by combing multi-GNSS observations as well as multi-source data derived from the Constellation Observing System for Meteorology, Ionosphere, and Climate (COSMIC), Interferometric Synthetic Aperture Radar (InSAR), radiosonde flights, etc. (Bender and Raabe, 2007; Bender et al., 2011; Wang et al., 2014; Alshawaf, 2013; Heublein et al., 2015; Benevides et al., 2015; Zhao et al., 2018c). For the improvement of tomographic models and resolution thereof, Perler et al. (2011) proposed a new parameterised tomographic method, which is capable of obtaining better tomographic results. Some methods concerned with the resolution of tomographic models, as well as the division of tomography areas, have been proposed such as the extended sequential successive filtering method, iterative reconstruction algorithm, etc. (Braun et al, 2003, 2004; Wang et al., 2014; Zhao et al., 2017a, 2018d; Chen and Liu, 2014). In addition, maximal use of GNSS signals penetrating from the side faces of tomography areas has obtained a significant improvement and is realised by introducing the water vapour scale factor (Yao and Zhao, 2016; Yao et al., 2016; Zhao et al., 2017b).

Currently, GNSS tomography technique is maturing in terms of theoretical and model aspects through almost 20 years of development, but its application in GNSS meteorology remains to be further investigated, therefore, we focus on capturing the signature of heavy rainfall events using the 2-d/4-d water vapour information derived from GNSS measurements in Hong Kong. The 2-d PWV time series is first analysed for correlation with heavy rainfall. Thereafter, the signatures of 4-d water vapour variations derived from GNSS tomography are investigated during heavy rainfall events while the tomographic modelling is resolved using the optimal weighting determination method.

\section{Fundamentals of GNSS meteorology}


Ann. Geophys. Discuss., https://doi.org/10.5194/angeo-2018-76

Manuscript under review for journal Ann. Geophys.

Discussion started: 23 July 2018

(c) Author(s) 2018. CC BY 4.0 License.

91 Satellite signals are delayed and bent when crossing the atmosphere, which adds ionosphere and troposphere delay: the former delay can be eliminated based on ionosphere free (IF) linear combination during the processing of GNSS measurement due to the dispersive nature of ionosphere delay (Dach and Walser, 2013). The latter delay can be divided into two parts: hydrostatic delay and wet delay. The first part of the tropospheric delay in a vertical direction, also called zenith hydrostatic delay (ZHD), can be precisely calculated by the Saastamoinen model (Saastamoinen, 1972) with the observed surface pressure while the second part can be estimated in the zenith direction using GNSS data. The second part is also called zenith wet delay (ZWD), from which the PWV can be calculated, thus forming a new concept: GNSS meteorology, as first proposed by Bevis et al. (1992). The calculation used in obtaining PWV is expressed as follows: the zenith total delay is first estimated by processing the GNSS measurements using the GNSS processing software such as Bernese, GAMIT, etc. The ZWD is then obtained by extracting the ZHD from ZTD and thus the PWV can be calculated based on the following equations (Saastamoinen, 1972; Askne and Nordius, 1987; Bevis et al., 1992):

$\mathrm{PWV}=\Pi \cdot \mathrm{ZWD}$

$$
\Pi=10^{6} /\left(\left(k_{2}^{\prime}+k_{3} / \mathrm{Tm}\right) \cdot R_{v} \cdot \rho_{w}\right)
$$

ZWD $=$ ZTD-ZHD

$$
\mathrm{ZHD}=\frac{0.002277 \times \mathrm{P}}{1-0.00266 \times \cos (2 \varphi)-0.00028 \times \mathrm{H}}
$$

Where $\Pi$ refers to the conversion factor, where $k_{2}^{\prime}, k_{3}$, and $R_{v}$ are constants with values of $22.1 \mathrm{~K} / \mathrm{mb}, 3.739 \times 10^{5} \mathrm{~K}^{2} / \mathrm{mb}$ and $461.495 \mathrm{~J} / \mathrm{kg} / \mathrm{K}$, respectively, $T_{\mathrm{m}}$ represents the weighted mean temperature, which is related to surface parameters such as temperature and pressure. Therefore, $T_{\mathrm{m}}$ is usually calculated based on the empirical model using the data from radiosonde or numerical weather model due to the observed layered meteorological parameters with are rarely obtained (Bevis et al., 1994; Yao et al., 2012). In the fourth formula in Eq. (1), P, H, and $\varphi$ represent the surface pressure $(\mathrm{hPa})$, geodetic height $(\mathrm{km})$, and station latitude (rad), respectively. In our study, the value of $T_{\mathrm{m}}$ is calculated based on the established regional $T_{\mathrm{m}}$ model using the radiosonde data and observed temperature (Section 3.2).

\subsection{Establishment of tomographic model}


Ann. Geophys. Discuss., https://doi.org/10.5194/angeo-2018-76

Manuscript under review for journal Ann. Geophys.

Discussion started: 23 July 2018

(c) Author(s) 2018. CC BY 4.0 License.

117 Generally, the slant wet delay (SWD) or slant water vapour (SWV) is considered as the input information for GNSS troposphere tomography (Flores et al., 2000; Hirahara, 2000; Skone and Hoyle, 2005; Rohm and Bosy, 2009; Chen and Liu., 2014) and the following equation gives an expression used to obtain SWV (Flores et al., 2000):

$$
\mathrm{SWV}_{a z i, e l e}=m_{w}(\text { ele }) \cdot \mathrm{PWV}+m_{w}(e l e) \cdot \cot (e l e) \cdot\left(G_{N S}^{w} \cdot \cos (a z i)+G_{W E}^{w} \cdot \sin (a z i)\right)
$$

Where $m_{w}$ presents the wet mapping function. ele and azi refer to the elevation angle and azimuth angle, respectively. $G_{N S}^{w}$ and $G_{W E}^{w}$ are the gradient parameters in the south-north and west-east directions, respectively.

If a sufficient number of SWVs derived from some stations in a regional CORS network can be obtained, the GNSS tomographic technique can be used to reconstruct the three-dimensional (3-d) distribution of atmospheric water vapour field. Therefore, a four-dimensional (4-d) water vapour information is a time series of such a 3-d tomographic result, which can reflect the regional atmospheric water vapour variations in both the spatial and temporal domains. As described by Flores et al. (2000), the linear observation equation between SWV and water vapour density can be expressed as follows:

Where $i, j, k$ represent the location of the area of interest in the longitudinal, latitudinal, and vertical directions, respectively, $d_{i j k}$ and $x_{i j k}$ refer to the distance travelled by satellite signals and the water vapour density remains to be estimated, respectively in the discretized voxels $(i, j, k)$. Therefore, the matrix form of the tomographic observation equation can be described as follows:

Where $\mathbf{y}$ represents the column vector of SWV derived from GNSS measurements. $\mathbf{A}$ and $\mathbf{x}$ are the coefficient matrix of distance penetrated by satellite rays and the column vector of water vapour density, respectively. Due to the large sparse matrix of observation equation, some constraints are required to overcome the influence caused by the ill-posed problem in the inversion of the tomographic normal equation 
Ann. Geophys. Discuss., https://doi.org/10.5194/angeo-2018-76

2014). In our study, both horizontal and vertical constraints are considered. The water vapour density in a certain voxel is regarded as the weighted mean value of its horizontal neighbouring voxels (Rius et al., 1997) and the negative exponential function is introduced to describe the relationship between the nearby voxels in the vertical direction while the coefficients of functional model are established using radiosonde data (Yao and Zhao, 2016). Consequently, the tomographic modelling can be expressed after imposing the constraints as:

$$
\left(\begin{array}{l}
\mathbf{y} \\
\mathbf{0} \\
\mathbf{0}
\end{array}\right)=\left(\begin{array}{l}
\mathbf{A} \\
\mathbf{H} \\
\mathbf{V}
\end{array}\right) \cdot \mathbf{x}
$$

Where $\mathbf{H}$ and $\mathbf{V}$ are the coefficient matrices of horizontal and vertical equations, respectively. To obtain a reasonable tomographic result from the above equation, an optimal tropospheric solution method is used, which can adaptively tune the weightings of different types of equations (Zhao et al., 2018d).

\section{Data description and establishment of a regional $T_{\mathrm{m}}$ model}

\subsection{Data description}

To validate the ability of GNSS technique in capturing the signature of atmospheric water vapour variation during heavy rainfall events, two periods of GNSS observations (19 to 27, July 2015 and 1 to 8, August 2015) from 13 GNSS stations in the CORS network of Hong Kong are selected in the experiment. Those two periods are selected because they correspond to a heavy rainfall event and a no-rainfall event, respectively according to hourly rainfall data from 45 rain gauges evenly distributed across this area (Figure 1). There is a radiosonde station located in this area where the radiosonde balloon is launched twice daily at UTC 00:00 and 12:00, respectively. The 20-years of radiosonde data from 1998 to 2017 are used to establish the regional $T_{\mathrm{m}}$ model in this study. In addition, the surface temperature and relative humidity are also selected to analyse their changes during those two periods. To explain the variations of surface temperature and relative humidity, the solar radiation data are also used in this study, which is derived from the CRU-NCEP Ver. 7 dataset. This dataset is a combination product of the CRU TS3.2 climate dataset and the NCEP reanalysis data. The temporal-spatial resolution of the solar radiation dataset are four times daily (UTC 00:00, 06:00, $12: 00$ and $18: 00$ ) and $0.5^{\circ} \times 0.5^{\circ}$, respectively. 
Ann. Geophys. Discuss., https://doi.org/10.5194/angeo-2018-76

Manuscript under review for journal Ann. Geophys.

Discussion started: 23 July 2018

(c) Author(s) 2018. CC BY 4.0 License.

GNSS observations are processed using Precise Point Positioning (PPP) data processing software

and the accuracy of the estimated ZTD parameters has been proved with the values of $7.2 \mathrm{~mm}$ and

$8.1 \mathrm{~mm}$ when compared to the GAMIT (v10.5) and Bernese (v5.2) software, respectively (Zhao et al., 2018a). The sampling rate of the estimated ZTD is $30 \mathrm{~s}$ and the data processing strategy has been presented previously (Zhao et al., 2018d). In addition, the gradient parameters in south-north and east-west directions are also estimated at intervals of $2 \mathrm{~h}$. The corresponding meteorological parameters, such as the surface pressure and temperature, are also obtained at the selected GNSS stations. Therefore, the precise ZHD can be calculated by the empirical model using the observed surface pressure. The conversion factor, as described in Eq. (1), is also obtained, in which $T_{\mathrm{m}}$ is calculated based on the established $T_{\mathrm{m}}$ model which will be introduced in the following section. Finally, the PWV time series, as well as the SWVs for the 13 selected GNSS stations, can be obtained. Five of the 45 rain gauges (R21, TMS, PEN, SSP, and KSC) are selected to analyse the variations in atmospheric water vapour during different weather conditions (Figure 1).

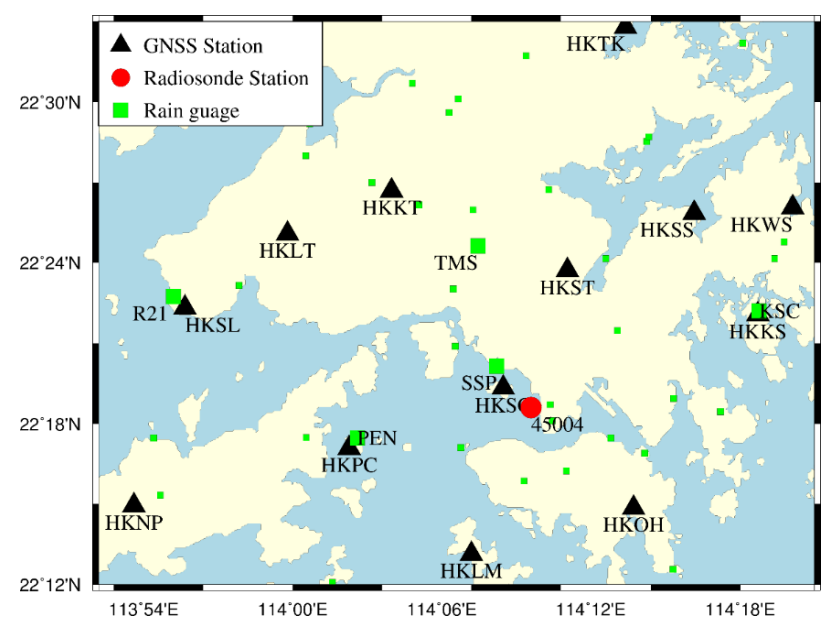

Figure 1. Geographic distribution of selected GNSS and radiosonde stations as well as the rain

$$
\text { gauges used in the experiment }
$$

\subsection{Establishment of the regional $T_{\mathrm{m}}$ model}

Due to the layered parameters such as water vapour pressure, temperature, etc. generally cannot be obtained for the location of GNSS stations, the $T_{\mathrm{m}}$ values of those stations are calculated based on the empirical model in this experiment. It has been proved that $T_{\mathrm{m}}$ is highly correlated with the 
variations of temperature, pressure, and the seasons (Bevis et al., 1992; Yao et al., 2012; Yao et al., 2014, 2015; Liu et al., 2018). Therefore, a regional $T_{\mathrm{m}}$ model which includes as parameters: temperature, surface pressure, and seasonal variation, is established and expressed as follows:

$$
\begin{array}{r}
T_{m}=T_{m 0}+a * T_{s}+b * P_{s}+c * \cos \left(2 \pi \frac{d o y}{365.25}\right)+d * \sin \left(2 \pi \frac{d o y}{365.25}\right) \\
+e * \cos \left(4 \pi \frac{d o y}{365.25}\right)+f * \sin \left(4 \pi \frac{d o y}{365.25}\right)
\end{array}
$$

Where $T_{m 0}, T_{s}$, and $P_{s}$ represent the initial value $T_{\mathrm{m}}$, surface temperature, and surface pressure, respectively; doy refers to the day of year; $a$ and $b$ are coefficients of $T_{s}$ and $P_{s}$, respectively, while $c$ to $f$ refer to the coefficients of the seasonal correction function. In our study, the coefficients in Eq. (6) were obtained by the least squares regression method using 20-year radiosonde data series for 45004 while the values of $a$ to $f$ are $129.1225,0.5370$, $-0.0023,0.358,0.813,-0.178$, and 0.255 , respectively.

The performance of the established $T_{\mathrm{m}}$ model is analysed and compared with the empirical formula proposed by Bevis et al. (1994). Statistical result of 20-years of radiosonde data reveals that the standard deviation and bias for the established $T_{\mathrm{m}}$ model and the empirical formula proposed by Bevis et al. (1994) are 2.04/0.0009 K and 3.41/2.53 K, respectively, which indicates that the established regional $T_{\mathrm{m}}$ model is superior to the empirical formula. The further to analyse the impact of $T_{\mathrm{m}}$ model error on the calculated PWV, a comparison experiment is carried out for radiosonde station 45004 with a variation in $T_{\mathrm{m}}$ of $1 \mathrm{~K}, 3 \mathrm{~K}, 5 \mathrm{~K}, 7 \mathrm{~K}$, and $9 \mathrm{~K}$, respectively and compared with the actual PWV values. Figure 2 shows the impact of $T_{\mathrm{m}}$ error on PWV for radiosonde station 45004 with a change in $T_{\mathrm{m}}$ of $1 \mathrm{~K}, 5 \mathrm{~K}$, and $9 \mathrm{~K}$, respectively. It can be clearly seen from Figure 2 that the impact of $T_{\mathrm{m}}$ model error on PWV is negligible. Statistical analysis shows that the PWV errors induced by the change in $T_{\mathrm{m}}$ of $1 \mathrm{~K}, 3 \mathrm{~K}, 5 \mathrm{~K}, 7 \mathrm{~K}$, and $9 \mathrm{~K}$ are 0.15 $\mathrm{mm}, 0.45 \mathrm{~mm}, 0.75 \mathrm{~mm}, 1.04 \mathrm{~mm}$, and $1.34 \mathrm{~mm}$, respectively under the condition of PWV >0 $\mathrm{mm}$, while the values are $0.18 \mathrm{~mm}, 0.54 \mathrm{~mm}, 0.91 \mathrm{~mm}, 1.27 \mathrm{~mm}$, and $1.63 \mathrm{~mm}$, respectively when PWV $>40 \mathrm{~mm}$. Therefore, the PWV errors caused by the established $T_{\mathrm{m}}$ model in this study are less than $0.4 \mathrm{~mm}$ and $0.5 \mathrm{~mm}$ when PWV $>0 \mathrm{~mm}$ and PWV $>40 \mathrm{~mm}$, respectively. Such result is deemed acceptable for the analysis of PWV variations with rainfall events (Akilan et al., 2015). 
Ann. Geophys. Discuss., https://doi.org/10.5194/angeo-2018-76

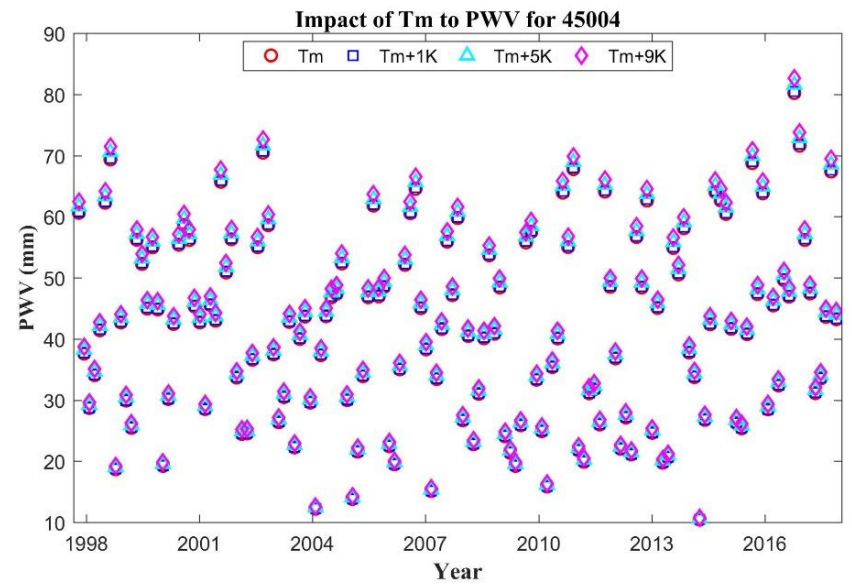

Figure 2. Impact of Tm to PWV for radiosonde station (45004) with a change in Tm by $1 \mathrm{~K}, 5 \mathrm{~K}$ and $9 \mathrm{~K}$, respectively over the period of 1998 to 2017

\section{Signature of 2-d/4-d variations in atmospheric water vapour during rainfall}

According to the recordings of 45 rain gauges derived from the Hong Kong Observatory, it is continuous rains in Hong Kong for the period of 19 to 27, July 2015 with the largest rainfall more than $300 \mathrm{~mm}$. The weather conditions are cloudy and sunny without rainfall happened for the period of 1 to 8 , August 2015. Therefore, those two periods are selected in this paper to investigate the variation characteristics of atmospheric water vapor.

\subsection{Cases of 2-d PWV time series change}

To capture the signature of PWV time series change in different weather conditions, the comparison between the 5-minute GNSS-derived PWV and hourly rainfall are performed for the periods of 19 to 27, July 2015 and 1 to 8, August 2015, respectively. Four GNSS stations (HKKS, HKSC, HKPC, and HKSL) and the surrounding rainfall gauges (HSC, SSP, PEN, and R21) are selected for this experiment.

Figure 3 shows the variations of 5-minute PWV time series data with hourly rainfall as well as the cumulative rainfall at those four stations for the period of 19 to 27 , July 2015 with its frequent rainfall events. It can be seen, from Figure 3, that the PWV time series show an increasing trend before the arrival of rainfall and reaches a relatively large value during rainfall, PWV then returns to its average value after rainfall. Additionally, the PWV time series data present a downward 
Ann. Geophys. Discuss., https://doi.org/10.5194/angeo-2018-76

Manuscript under review for journal Ann. Geophys.

Discussion started: 23 July 2018

(c) Author(s) 2018. CC BY 4.0 License.

241 trend at four stations during this period. The cumulative rainfall first increased at about UTC 11:00,

24220 July, 2015 with different levels reached and the event terminated at UTC 12:00, 23 July, 2015.

243 The largest cumulative rainfall reached about $250 \mathrm{~mm}$ while the minimum recorded rainfall was about $100 \mathrm{~mm}$ across the four selected gauge stations. The PWV time series is also analysed at those four stations for the period from 1 to 8 , August, 2015 in which no rainfall was recorded (Figure 4). Figure 4 shows the 5-minute PWV time series changes from which it can be found that PWV does not show any continuous increasing trend when there is no rainfall, but the range of PWV variation is relatively large (from about $35 \mathrm{~mm}$ to greater than $55 \mathrm{~mm}$ ). Comparing the PWV time series in Figures 3 and 4, it also can be observed that the PWV values during rainfall are much larger than that of no rainfall time. In addition, 5-minute surface temperature and relative humidity data are also analysed during those two periods. The first and second columns of Figure 5 show the changes in temperature and relative humidity for the period 19 to 27 , July, 2015. It also can be seen that the temperature and relative humidity do not show any trend during heavy rainfall but show a tendency to run counter to one another on 19,26 , and 27 , July. one explanation is that heavy rainfall breaks the trend in temperature and relative humidity for the period from 20 to 25 , July, 2015. The third column of Figure 5 shows the changes in solar radiation for this period, from which it can be observed that the solar radiation undergoes a day periodic change. To verify this explanation, the variations of temperature and relative humidity, as well as those in solar radiation, are also presented at those four stations for period without rainfall (Figure 6): temperature and solar radiation show a similar trend while relative humidity presents the opposite trend. Additionally, it can be observed from the first and third columns of Figures 6 that the maximum values of solar radiation and temperature occurred at UTC 4:00 (local time 12:00) while the minimum value of relative humidity also occurred at that time. The phenomenon found in Figure 6 further confirmed the explanation presented above. In addition, the values of solar radiation are more fluctuated at the four stations that the part of solar radiation is decreased by cloud cover during heavy rain. 
Ann. Geophys. Discuss., https://doi.org/10.5194/angeo-2018-76

Manuscript under review for journal Ann. Geophys.

Discussion started: 23 July 2018

(c) Author(s) 2018. CC BY 4.0 License.
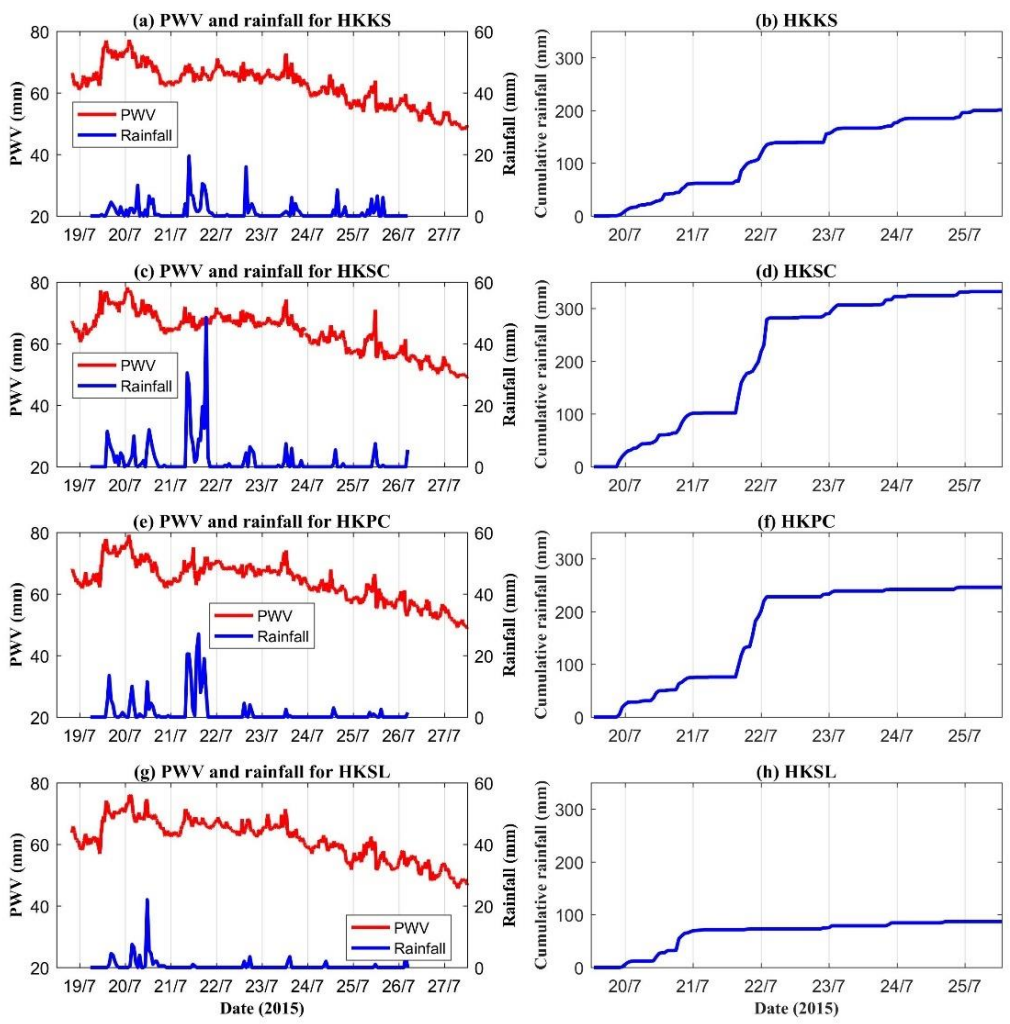

Figure 3. Variations of 5-minutely PWV time series with hourly rainfall and the cumulative

rainfall for HKKS, HKSC, HKPC and HKSL stations over the period of 19 to 27, July 2015, the

first column represents the variations of PWV and rainfall and the second column refers to the
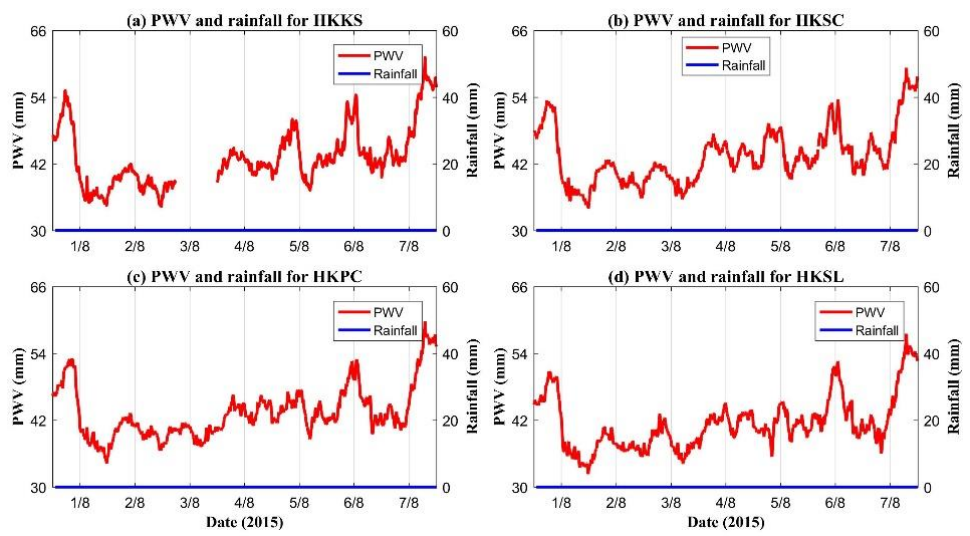

Figure 4. Variations of 5-minutely PWV time series with hourly rainfall at (a) HKKS, (b) HKSC, 
Ann. Geophys. Discuss., https://doi.org/10.5194/angeo-2018-76

Manuscript under review for journal Ann. Geophys.

Discussion started: 23 July 2018

(c) Author(s) 2018. CC BY 4.0 License.
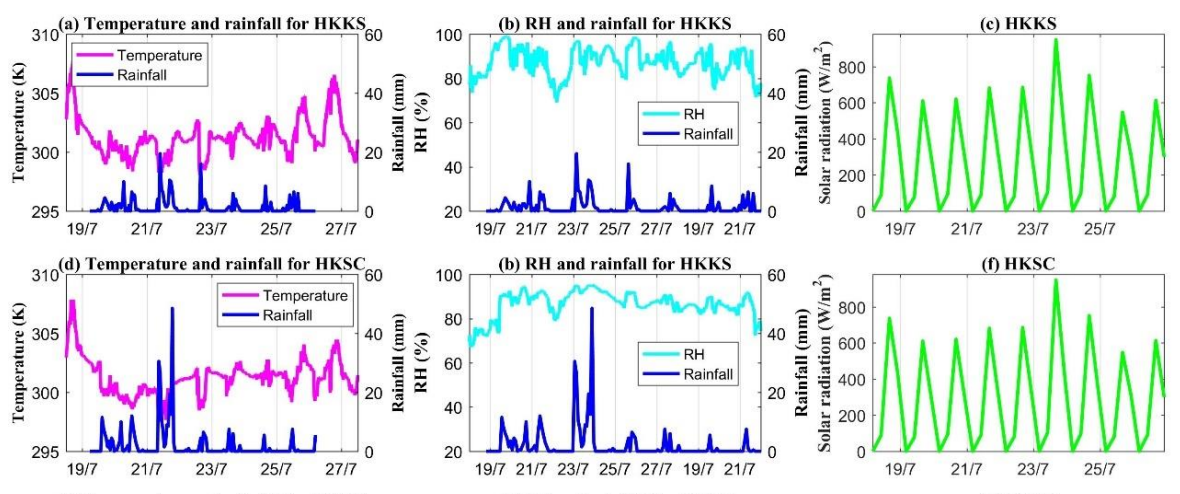

310 (g) Temperature and rainfall for HKPC 60
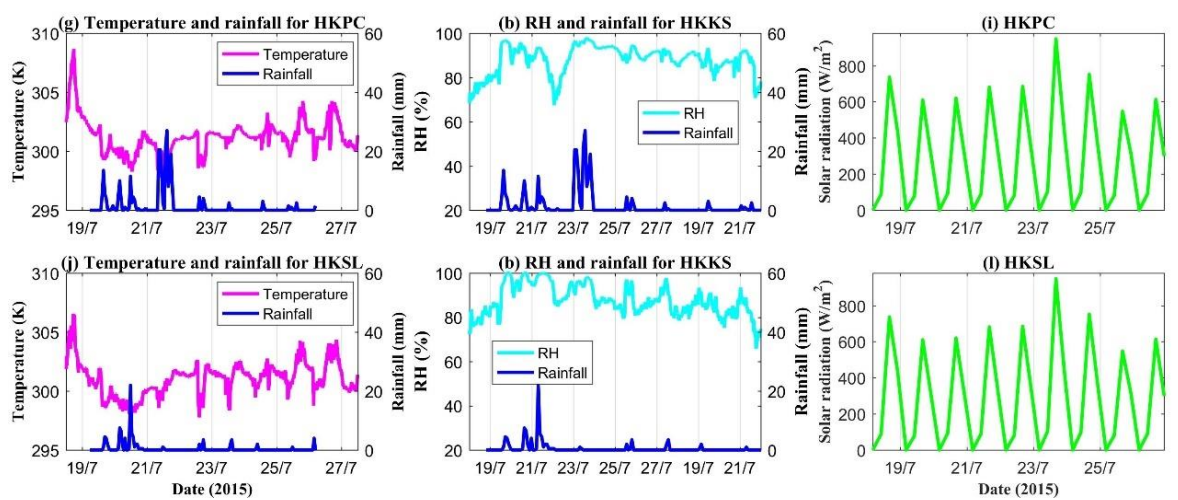

Figure 5. Changes of temperature, relative humidity with rainfall as well as the solar radiation at

HKKS, HKSC, HKPC and HKSL stations over the period of 19 to 27, July 2015, the first column

represents the variations of temperature and rainfall, the second column refers to the variations of 
Ann. Geophys. Discuss., https://doi.org/10.5194/angeo-2018-76
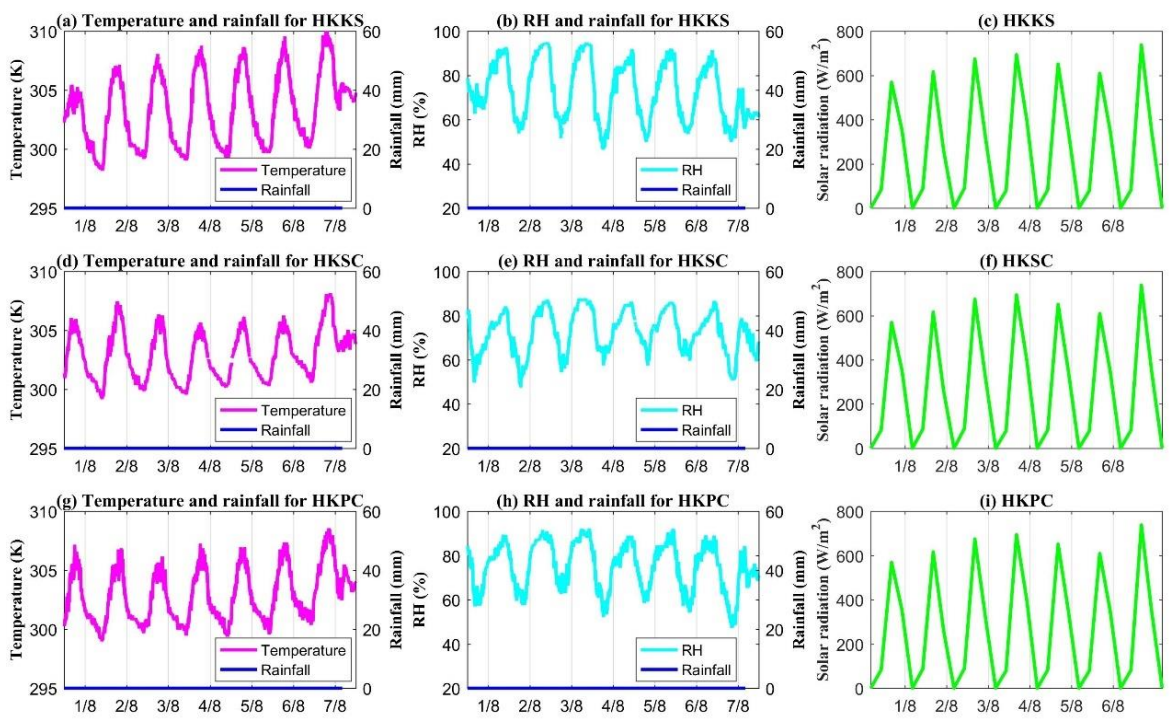

(i) HKPC
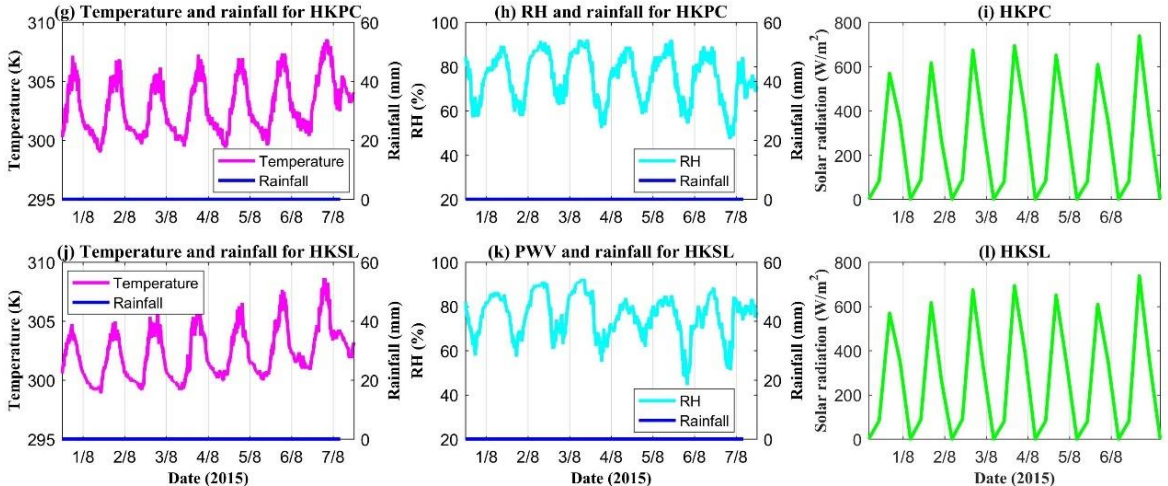

(I) HKSL

Figure 6 . Changes of temperature, relative humidity with rainfall as well as the solar radiation at

HKKS, HKSC, HKPC and HKSL stations over the period of 1 to 7, August 2015, the first column

represents the variations of temperature and rainfall, the second column refers to the variations of

$\mathrm{RH}$ and rainfall and the third column refers to the solar radiation

\subsection{Cases of water vapour profile variation during heavy rainfall}

The variations in 4-d atmospheric water vapour are also analysed during heavy rainfall. In this section, the tomographic technique is introduced and the research area is discretised. There are 7 and 8 grids in longitudinal and latitudinal directions, respectively and 29 layers in vertical direction. Therefore, there are total $7 \times 8 \times 29$ voxels. The horizontal steps are $0.05^{\circ}$ and $0.06^{\circ}$ in longitudinal and latitudinal directions, respectively while the inhomogeneous vertical step is selected based on the water vapour distribution at different altitudes (Yao and Zhao, 2017) with resolutions of $0.2 \mathrm{~km} \times 10,0.3 \mathrm{~km} \times 8,0.4 \mathrm{~km} \times 6,0.6 \mathrm{~km} \times 4$, and $0.8 \mathrm{~km} \times 1$, respectively. A 
Ann. Geophys. Discuss., https://doi.org/10.5194/angeo-2018-76

Manuscript under review for journal Ann. Geophys.

Discussion started: 23 July 2018

(c) Author(s) 2018. CC BY 4.0 License.

comparison of water vapour density profiles derived from tomographic result and radiosonde data at the location of radiosonde station 45004 is first presented (Figure 7) to validate the performance of the GNSS tomographic technique. It can be seen from the Figure 7 that the profiles derived from tomographic results were consistent with the observed radiosonde data at most altitudes, which manifests the ability of the GNSS tomographic technique to reflect variations in water vapour content during rainfall. The detailed information about the accuracy of tomographic result has been presented in Zhao et al. (2018d). In addition, it also can be observed that more sophisticated water vapour variations detected vertically (with 29 layers) can be provided by the GNSS tomographic technique than by radiosonde data.

Two heavy rainfall periods are selected in this experiment: the first at UTC 18 to 22, 21 July 2015 and three rain gauges are used to analyse the variations in water vapour profiles. The hourly rainfall for those three rain gauges is presented in Table 1 while the water vapour profile variations over time for SPP, PEN, and TKL are shown in Figures 8 to 10. From those three figures it can be observed that atmospheric water vapour profile undergoes vertical movement about 1-2 hours before the arrival of heavy rain, which is reflected by the fluctuating water vapour density at different altitudes. For the SPP rain gauge, it can be seen that the water vapour content in the lower atmosphere, from an altitude of about $1.8-2.5 \mathrm{~km}$ to $3.5 \mathrm{~km}$ while the water vapour content decreases from 4-5 $\mathrm{km}$ to $3.5 \mathrm{~km}$. It can also be observed from PEN and TKL rain gauges that an upward and downward movement happened in the atmospheric water vapour profile in the lower, and upper atmosphere, respectively: this results in a large increase in atmosphere water vapour at altitudes of about $2.3 \mathrm{~km}$ and $1.6 \mathrm{~km}$, respectively (especially at PEN). The upward and downward motions of atmospheric water vapor in the lower and upper atmosphere are expected to the occurrence of the strong convective weather. In addition, it was found that the variations of water vapour profiles in vertical direction at station TKL are weaker than that from stations PEN and SPP. A possible explanation is that the rainfall was $30.5 \mathrm{~mm}$ and $20.5 \mathrm{~mm}$ for PEN and SPP at UTC 20, 21 July 2015 while the value is only $1 \mathrm{~mm}$ at station TKL at UTC 21, 21 July 2015 (Table 1). The above phenomenon indicates that the significant vertical motion of water vapour profile was possibly induced by heavy rainfall. The variations in water vapour profiles during rainfall reveal that the significant vertical motion of water vapour occurred before the onset of rainfall while the water vapour profiles were relatively stable during rainfall events. 
Ann. Geophys. Discuss., https://doi.org/10.5194/angeo-2018-76

Manuscript under review for journal Ann. Geophys.

Discussion started: 23 July 2018

(c) Author(s) 2018. CC BY 4.0 License.

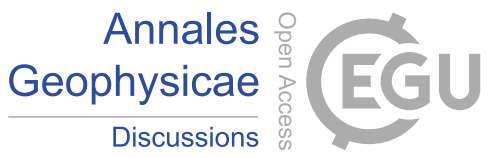

In addition, the time series of water vapour density profiles, at a temporal resolution of 1 minute, for the three rain gauges are also presented in Figure 11. From which it can be seen that the vertical water vapour density profile undergoes a significant vertical motion about 1-2 hours before the arrival of rain (black dotted rectangles, Figure 11) while the profiles are relatively stable during rain. By comparing the Figures $8-10$, it also can be found that the vertical variations of water vapour density profiles at SPP and PEN stations 1 hour before rainfall are more active than that at TKL station: this can be explained by considering that the continued heavy rainfall happened at SPP and PEN stations while the TKL had little rainfall (Table 1), therefore, the continuing water vapour transportation in the vertical direction existed in the lower atmosphere at stations SPP and PEN.
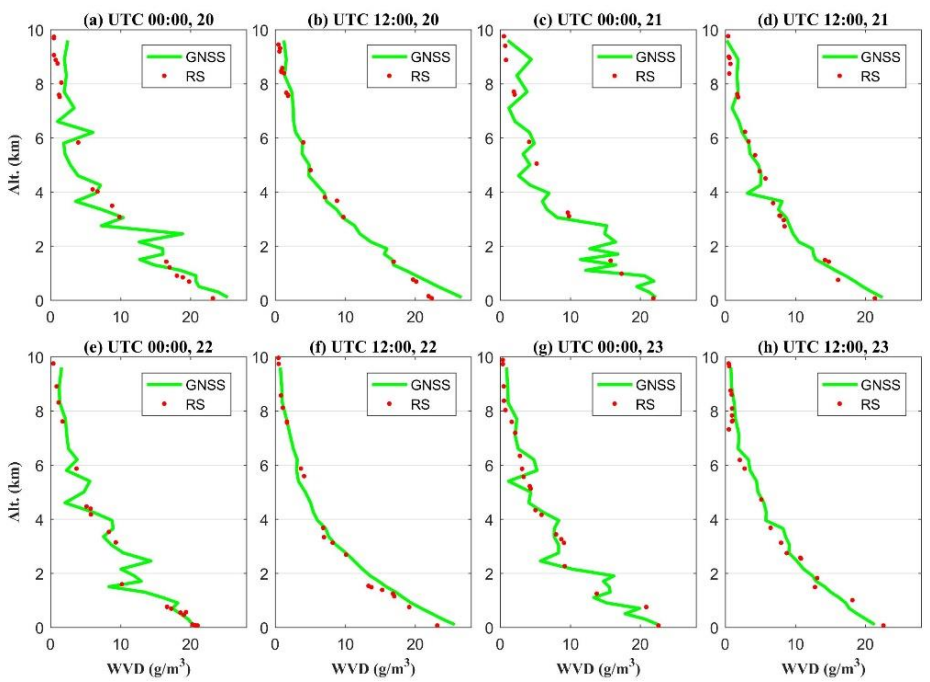

Figure 7. Distribution of water vapor density (WVD) profiles at UTC 00:00 and 12:00,

respectively derived from the GNSS tomographic result (green curve) and the radiosonde data of the observed height (red hot) for the location of radiosonde station (45004) over the period of 20

Table 1 Hourly Rainfall information of the selected four rain gauges over period of UTC 19 to 23,

21 July 2015 (Unit: mm)

\begin{tabular}{llll} 
Station & SPP & PEN & TKL \\
\hline
\end{tabular}


Ann. Geophys. Discuss., https://doi.org/10.5194/angeo-2018-76

Manuscript under review for journal Ann. Geophys.

Discussion started: 23 July 2018

(c) Author(s) 2018. CC BY 4.0 License.

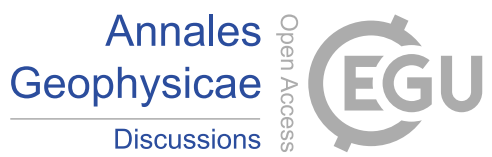

(c) (i)

\begin{tabular}{lccc}
\hline 19, 21 July & 0 & 0 & 0 \\
20, 21 July & 30.5 & 20.5 & 0 \\
21, 21 July & 26.5 & 20.5 & 1.0 \\
22, 21 July & 10.5 & 13.5 & 1.5 \\
23, 21 July & 7.5 & 2.5 & 1.5 \\
\hline
\end{tabular}

347
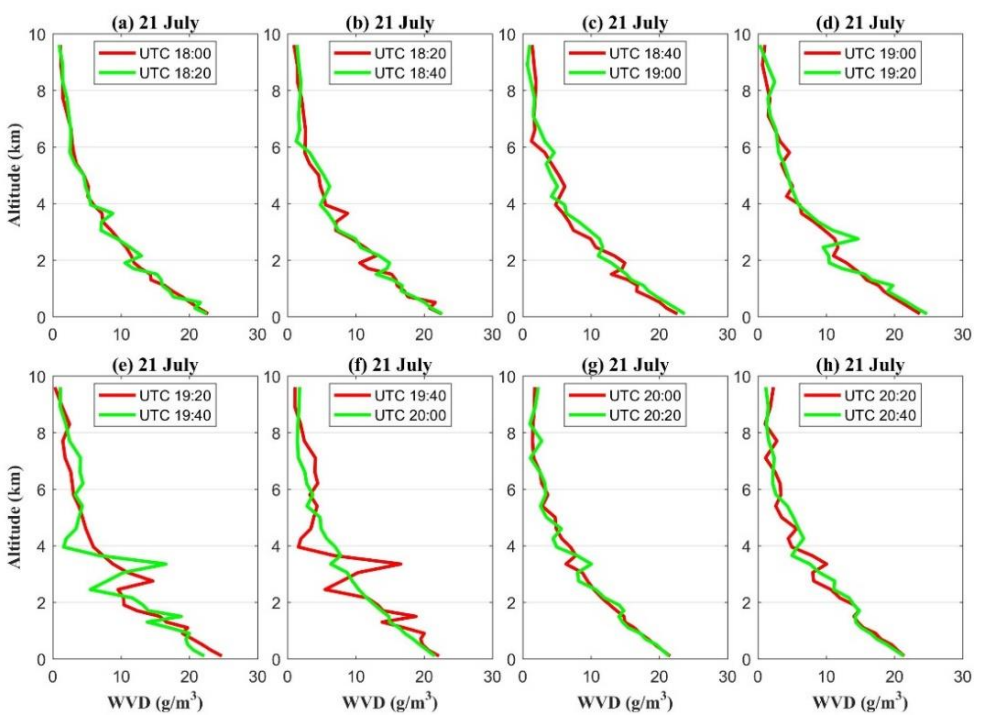

Figure 8. Distribution of water vapor density Profiles (WVD) derived from GNSS tomographic

result with the temporal resolution of 20 minutes for the location of SPP rain gauge over the 
Ann. Geophys. Discuss., https://doi.org/10.5194/angeo-2018-76

Manuscript under review for journal Ann. Geophys.

Discussion started: 23 July 2018

(c) Author(s) 2018. CC BY 4.0 License.
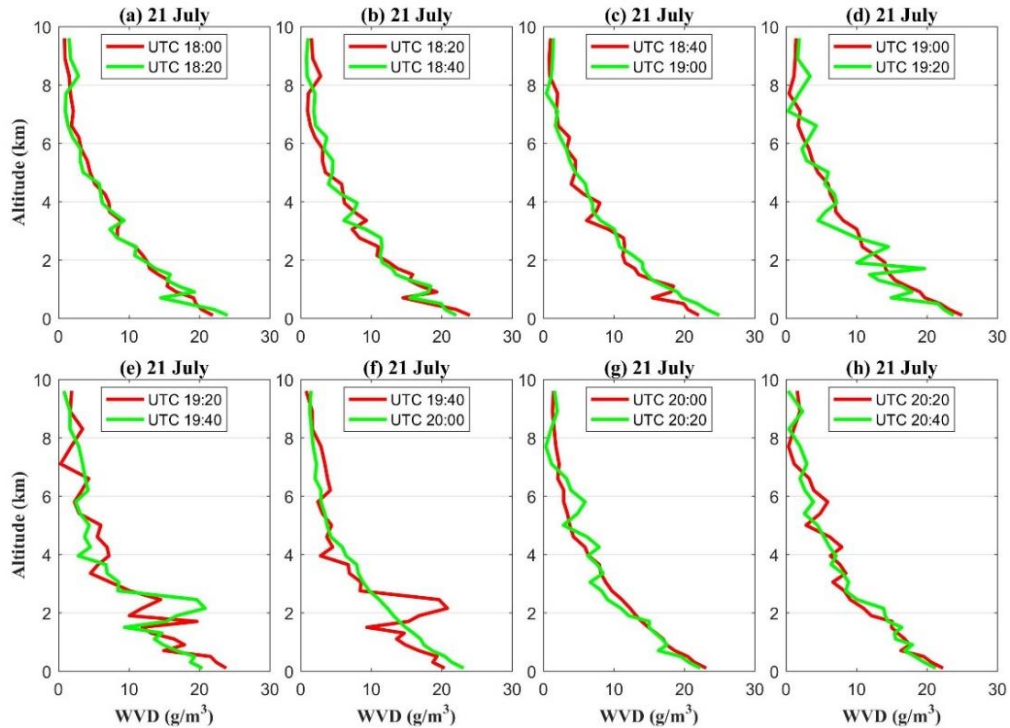

Figure 9. Distribution of water vapor density Profiles (WVD) derived from GNSS tomographic result with the temporal resolution of 20 minutes for the location of PEN rain gauge over the period of UTC 18:00 to 20:40, 21 July 2015
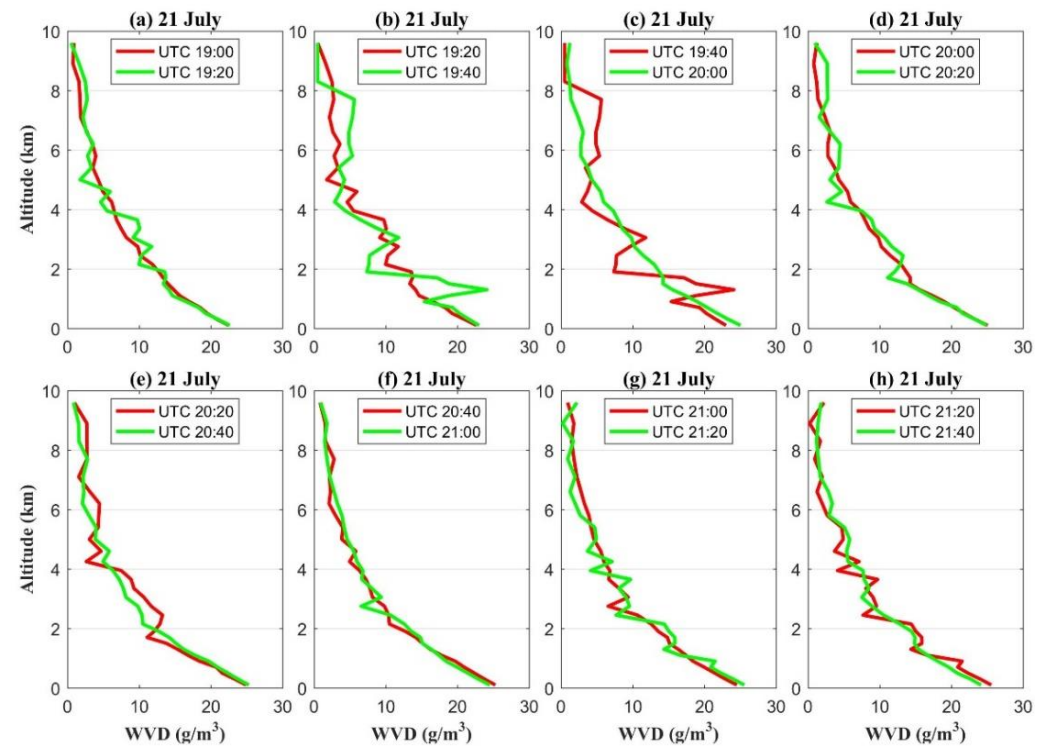

Figure 10. Distribution of water vapor density Profiles (WVD) derived from GNSS tomographic result with the temporal resolution of 20 minutes for the location of TKL rain gauge over the period of UTC 19:00 to 21:40, 21 July 2015 
Ann. Geophys. Discuss., https://doi.org/10.5194/angeo-2018-76

Manuscript under review for journal Ann. Geophys.

Discussion started: 23 July 2018

(c) Author(s) 2018. CC BY 4.0 License.

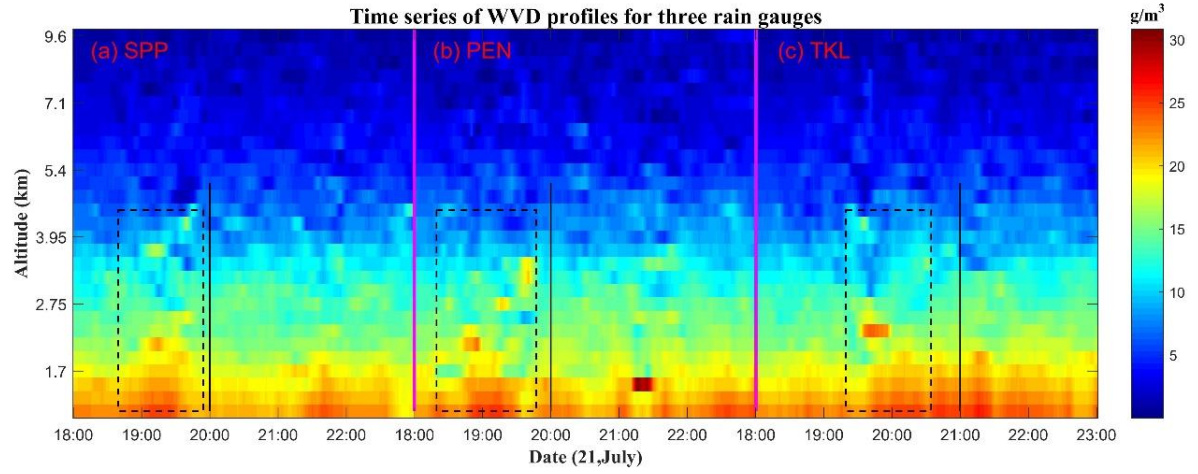

Figure 11. Time series of water vapor density (WVD) profiles derived from GNSS tomographic result with the temporal resolution of 1 minute for the locations of three rain gauges over the period of UTC 18:00 to 23:00, 21 July 2015, where the rainfall happened at UTC 20:00 21 July for (a) SPP and (b) PEN rain gauges while the rainfall occurred at UTC 21:00 21 July for (c) TKL rain gauge. The WVD profiles with drastic vertical motion are marked by the black dotted rectangles for three rain gauges while the locations of black solid lines are the starting time of rainfall

To verify the phenomenon observed above, another period (UTC 0 to 4, 23 July 2015) at PEN and TMS rain gauges is selected while the hourly rainfall information is presented in Table 2. Figures 12 and 13 both reflect that the change in water vapour profiles at PEN and TMS stations are similar to that of above conditions. The water vapour content above PEN and TMS is increased at altitudes of $2.5 \mathrm{~km}$ and $3.2 \mathrm{~km}$, respectively, some 1-2 hours before onset of rainfall and returns to its average value at the moment that the rainfall is about to begin. One possible explanation for this is that: before onset of rainfall, the atmospheric water vapour was conditionally unstable with intense vertical movement as proved by Brenot et al., (2006). The ascending motion of water vapour in the lower atmosphere and the descending motion of water vapour in the upper atmosphere significantly increases the water vapour content at a certain height where hydrometeors are formed. The hydrometeors consist of liquid water and icy hydrometeors, formation of which is random in time and space. Due to the delays to satellite signals induced by liquid water and icy species generally being much smaller than the water vapour species-induced delays, these are unavailable in the case of GNSS observations, therefore, GNSS tomography 
Ann. Geophys. Discuss., https://doi.org/10.5194/angeo-2018-76

Manuscript under review for journal Ann. Geophys.

Discussion started: 23 July 2018

(c) Author(s) 2018. CC BY 4.0 License.

cannot reflect the distribution of hydrometeors and the tomographic profiles show a

hydrometeors particles form raindrops with a continual accretion thereof. When the atmosphere is unable to support the weight of the formed raindrop, the drop falls as rain. The formation of hydrometeors particles and raindrops require some time, hence the intense vertical movement of atmospheric water vapour before onset of rainfall. The time taken to generate hydrometeors and raindrops provides the possibility of now-casting rainfall based on the GNSS technique.

\begin{tabular}{lll}
\multicolumn{3}{c}{2015 (Unit: mm) } \\
\hline 0, 23 July & 0 & 0 \\
1, 23 July & 0 & 0 \\
2, 23 July & 4.5 & 16.5 \\
3, 23 July & 0.5 & 4.5 \\
4, 23 July & 0 & 0.5 \\
\hline
\end{tabular}
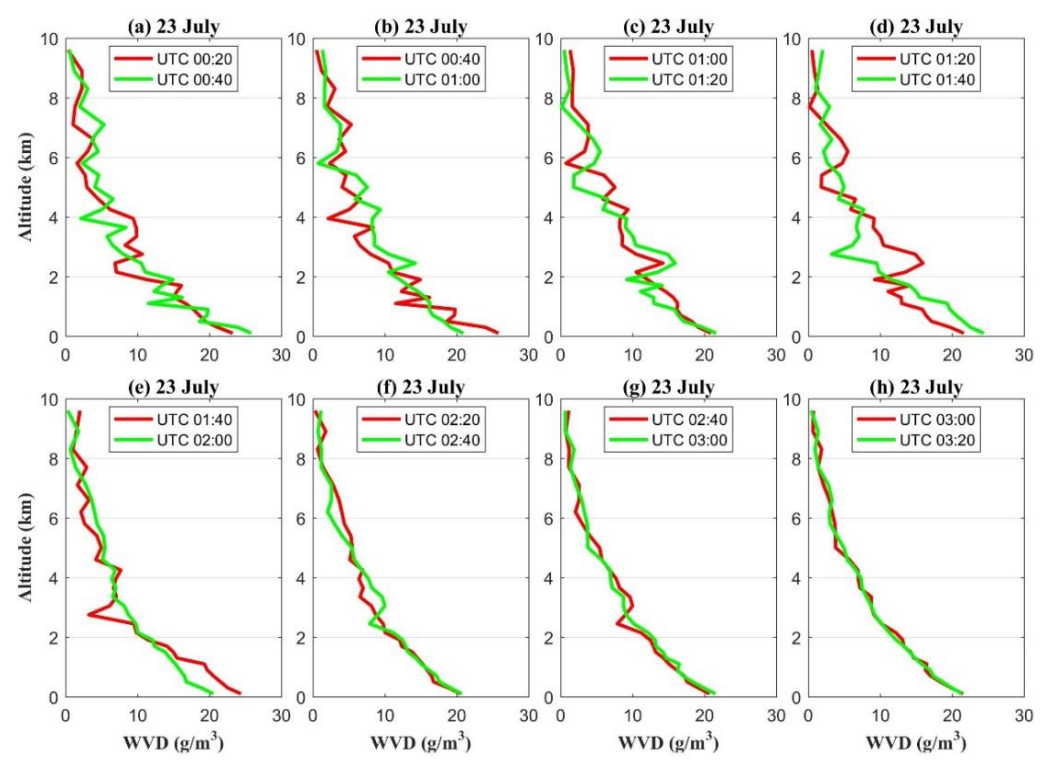

Figure 12. Distribution of water vapor density (WVD) profiles from GNSS tomographic result 
Ann. Geophys. Discuss., https://doi.org/10.5194/angeo-2018-76

Manuscript under review for journal Ann. Geophys.

Discussion started: 23 July 2018

(c) Author(s) 2018. CC BY 4.0 License.
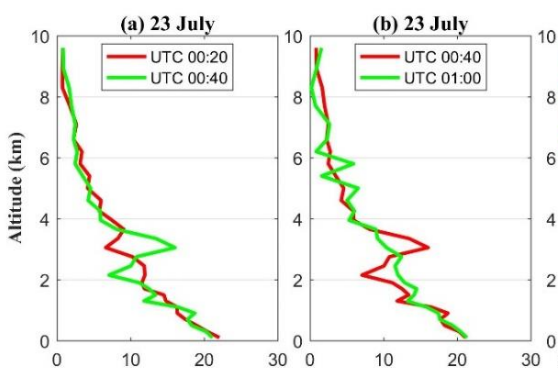

(c) 23 July
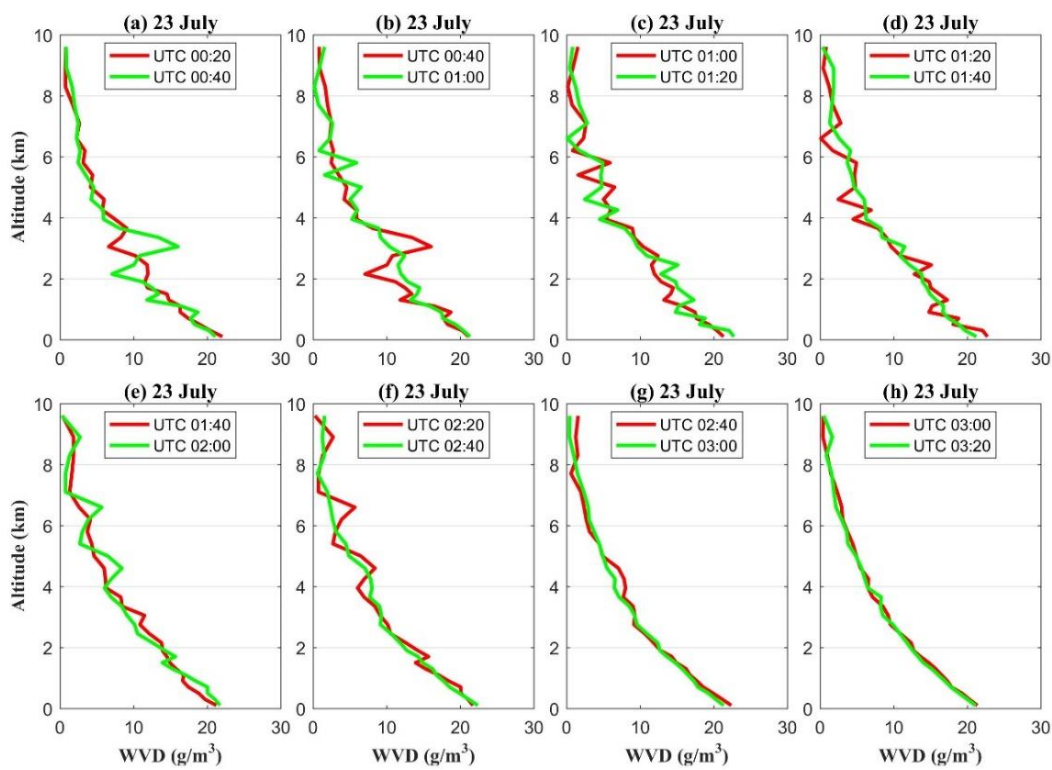

Figure 13. Distribution of water vapor density (WVD) profiles from GNSS tomographic result with the temporal resolution of 20 minutes for the location of TMS rain gauge over the period of

UTC 00:20 to $03: 20,23$ July 2015

The 4-d distribution of atmospheric water vapour for the period UTC 18:00 to 20:20, 21 July 2015 is presented with a spatio-temporal resolution of 20 minutes and 20 layers to an altitude of $5 \mathrm{~km}$, respectively (Figure 14). According to the hourly rainfall recordings at 45 rain gauges in this area, most parts of the experimental area suffered heavy rainfall at UTC 20:00, 21 July 2015 that lasted for several hours. It can be found, from Figure 14, that the significant vertical motion of water vapour observed over the period from UTC 18:00 to 19:40 returns to its relatively stable condition at UTC 20:00 but with a lower water vapour content in most layers. The main reason for this may be water vapour transfer to the liquid water particles and icy hydrometeors, which have little impact on the delay of satellite signals and cannot be observed by the GNSS technique. For the period of heavy rainfall that occurred after UTC 20:00, the atmospheric water vapour profiles were relatively stable with slight vertical variation in water vapour content. In addition, it can be concluded that the place at which hydrometeors were generated in the lower atmosphere is 
Ann. Geophys. Discuss., https://doi.org/10.5194/angeo-2018-76

Manuscript under review for journal Ann. Geophys.

Discussion started: 23 July 2018

(c) Author(s) 2018. CC BY 4.0 License.

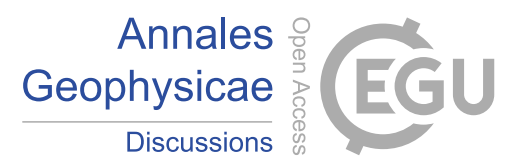

418 possibly where rainfall occurred. Therefore, where heavy rainfall occurred is possibly predictable

419 before the onset of rainfall according to the 4-d atmospheric water vapour variations at different

420 altitudes derived from GNSS tomography. It also can be found that there is the horizontal motion

421 of atmospheric water vapor as well in different layers, especially at the bottom layers. This is

422 because the happening of rainfall requires the enough water vapor supplement, the horizontal

423 motion of water vapor at the bottom layers implies the continuous water vapor transportation.
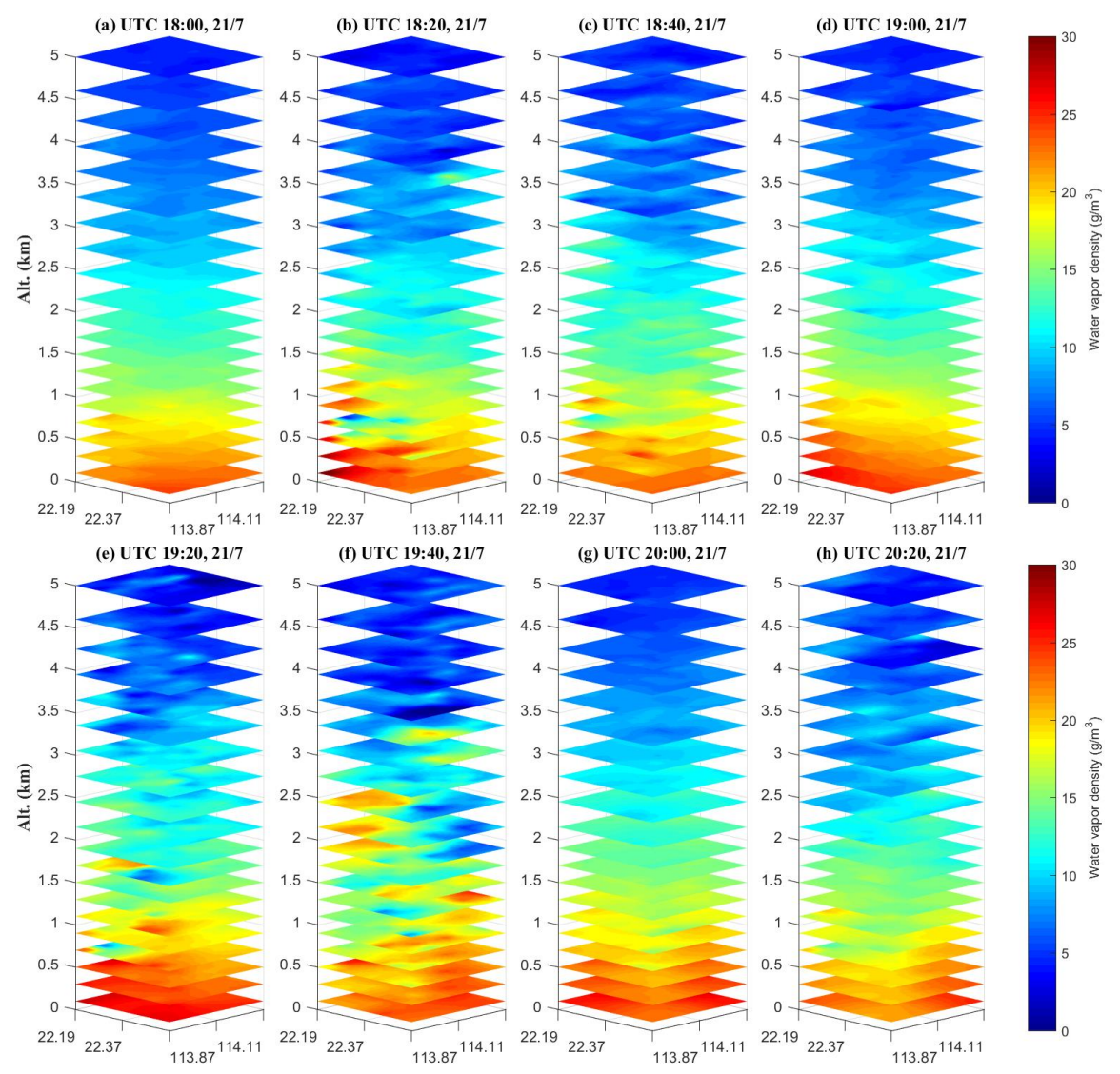

424

Figure 14. Three-dimensional distribution of atmospheric water vapor density derived from GNSS tomographic result with the temporal resolution of 20 minutes over the period of UTC 18:00 to 20:20, 21 July 2015 with 20 layers from the ground to $5 \mathrm{~km}$ 
Ann. Geophys. Discuss., https://doi.org/10.5194/angeo-2018-76

Manuscript under review for journal Ann. Geophys.

Discussion started: 23 July 2018

(c) Author(s) 2018. CC BY 4.0 License.

431 GNSS sensing water vapour is an effective, practical technique, which able to the reflect 2-d and

432 4-d atmospheric water vapour variations during the formation and lifecycle of heavy rainfall. 2-d

PWV time series data derived from GNSS observations are first compared with hourly rainfall measurements, which reveals the continuous increasing trend in PWV before the onset of rainfall and returns to its average value after rainfall. In addition, it is also found that the variations of surface temperature and relative humidity have day-periodicity and are mainly caused by the variations in solar radiation during no rain periods, but their changes are disturbed by rainfall during rainfall periods.

A 4-d water vapour reconstruction technique is performed using GNSS data to analyse the vertical water vapour movement during rainfall period. It is found that significant vertical motion occurred about 1-2 hours before the arrival of rainfall and this was reflected by the ascending and descending motions of water vapour in the lower and upper atmosphere, respectively.

Hydrometeors are then formed at a certain altitude where sufficient water vapour was concentrated.

The formation of hydrometeors and raindrops requires some time, which makes it possible for the forecasting of now-casting rainfall. At the moment of onset of rainfall, the water vapour profiles return to their average values at different altitudes and show a relative stable condition but with a decreasing trend in the water vapour content in the lower atmosphere. In addition, the place where the rainfall is most possible happened may be forecasted by locating out the location of the point of decreasing water vapour content in the lower atmosphere. These results revealed that rainfall had a direct relationship with atmospheric water vapour content as well as the vertical variations of water vapour density profiles, which further manifested the significant potential of the GNSS technique for monitoring and forecasting during the lifecycle of rainfall event.

Acknowledgement: The authors would like to thank IGAR for providing access to the web-based IGAR data. The Lands Department of HKSAR is also acknowledge for providing GNSS and meteorological data from the Hong Kong Satellite Positioning Reference Station Network (SatRef) and the corresponding rainfall data. This research was supported by the Key projects of National 
Ann. Geophys. Discuss., https://doi.org/10.5194/angeo-2018-76

Manuscript under review for journal Ann. Geophys.

Discussion started: 23 July 2018

(c) Author(s) 2018. CC BY 4.0 License.

Annales

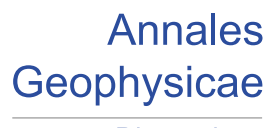

Discussions

\section{References:}

Akilan A.; Azeez K K A.; Balaji S, et al. GPS derived Zenith Total Delay (ZTD) observed at tropical locations in South India during atmospheric storms and depressions. Journal of Atmospheric and Solar-Terrestrial Physics. $2015,125,1-7$.

Alshawaf, F. Constructing water vapor maps by fusing InSAR, GNSS and WRF data. Karlsruhe, Karlsruher Institut für Technologie (KIT), Dissertation. 2013.

Askne J.; Nordius H. Estimation of tropospheric delay for microwaves from surface weather data[J]. Radio Science. 1987, 22(03), 379-386.

Bai, Z. "Near-real-time GPS sensing of atmospheric water vapour," Ph.D. dissertation, Queensland Univ. of Technol., Brisbane, Queensland, 2004

Barindelli, S.; Realini, E., Venuti, G.; Fermi, A \& Gatti, A. Detection of water vapor time variations associated with heavy rain in northern Italy by geodetic and low-cost GNSS receivers. Earth Planets \& Space, 2018, 70(1), 28.

Bender M.; Raabe A. Preconditions to ground based GPS water vapour tomography. Annales geophysicae. 2007, 25(8), 1727-1734.

Bender M.; Stosius R.; Zus F.; et al. GNSS water vapour tomography-Expected improvements by combining GPS, GLONASS and Galileo observations. Advances in Space Research. 2011, 47(5), 886-897.

Bender M.; Dick G.; Ge M.; et al. Development of a GNSS water vapour tomography system using algebraic reconstruction techniques. Advances in Space Research, 2011, 47(10), 1704-1720.

Benevides P.; Catalao J.; Miranda P M A. On the inclusion of GPS precipitable water vapour in the nowcasting of rainfall. Natural Hazards and Earth System Sciences. 2015b, 15(12), 2605-2616.

Benevides P.; Nico G.; Catalao J.; et al. Merging SAR interferometry and GPS tomography for high-resolution mapping of 3D tropospheric water vapour. Geoscience and Remote Sensing Symposium (IGARSS), 2015 IEEE International. IEEE, 2015a, 3607-3610.

Bennitt G V.; Jupp A. Operational assimilation of GPS zenith total delay observations into the Met Office numerical weather prediction models. Monthly Weather Review, 2012, 140(8), 2706-2719.

Bevis M.; Businger S.; Herring T A.; et al. GPS meteorology: Remote sensing of atmospheric water vapor using the Global Positioning System. Journal of Geophysical Research: Atmospheres. 1992, 97(D14), 15787-15801.

Bevis M.; Businger S.; Chiswell S.; et al. GPS meteorology: Mapping zenith wet delays onto precipitable water[J]. Journal of applied meteorology, 1994, 33(3), 379-386.

Bi Y.; Mao J.; Li C. Preliminary results of 4-D water vapor tomography in the troposphere using GPS. Advances in atmospheric sciences, 2006, 23(4), 551-560.

Braun, John Joseph. Remote sensing of atmospheric water vapor with the global positioning system. Geophysical Research Letters, 2004, 20(23), 2631-2634.

Braun J.; Rocken C.; Liljegren J. Comparisons of line-of-sight water vapor observations using the global positioning system and a pointing microwave radiometer. Journal of Atmospheric and Oceanic Technology, 2003, 20(5), 606-612.

Brenot H.; Neméghaire J.; Delobbe L.; et al. Preliminary signs of the initiation of deep convection by GNSS. Atmospheric Chemistry and Physics, 2013, 13(11), 5425-5449.

Brenot, H., Ducrocq, V., Walpersdorf, A., Champollion, C., \& Caumont, O. (2006). GPS zenith delay sensitivity evaluated from high - resolution numerical weather prediction simulations of the 8 - 9 September 2002 flash flood over southeastern France. Journal of Geophysical Research: Atmospheres, 111(D15).

Chen B, Liu Z. Voxel-optimized regional water vapor tomography and comparison with radiosonde and numerical weather model. Journal of geodesy, 2014, 88(7), 691-703.

Dach R. and Walser P. "Bernese GNSS software version 5.2,” Astronomical Inst., Univ. of Bern, Bern, 2013. 
Ann. Geophys. Discuss., https://doi.org/10.5194/angeo-2018-76

Manuscript under review for journal Ann. Geophys.

Discussion started: 23 July 2018

(c) Author(s) 2018. CC BY 4.0 License.

De Haan S. Assimilation of GNSS ZTD and radar radial velocity for the benefit of very-short-range regional weather forecasts. Quarterly Journal of the Royal Meteorological Society. 2013, 139(677), 2097-2107.

Flores A.; Ruffini G.; Rius A. 4D tropospheric tomography using GPS slant wet delays//Annales Geophysicae. Springer-Verlag, 2000, 18(2), 223-234.

Guerova G.; Jones J.; Dousa J.; et al. Review of the state of the art and future prospects of the ground-based GNSS meteorology in Europe. Atmospheric Measurement Techniques, 2016, 9(11), 1-34.

Heublein M.; Zhu X X.; Alshawaf F.; et al. Compressive sensing for neutrospheric water vapor tomography using GNSS and InSAR Observations[C]//Geoscience and Remote Sensing Symposium (IGARSS), 2015 IEEE International. IEEE, 2015, 5268-5271.

Hirahara K. Local GPS tropospheric tomography. Earth, planets and space, 2000, 52(11), 935-939.

JMA (2013) Outline of the operational numerical weather prediction at the Japan Meteorological Agency. Appendix to WMO technical progress report on the global data-processing and forecasting system (GDPFS) and $\begin{array}{llll}\text { numerical weather } & \text { prediction } & \text { research. }\end{array}$ http://www.jma.go.jp/jma/jma-eng/jma-center/nwp/outline2013-nwp/index.htm. Accessed 30 Aug 2017

Liu J.; Yao Y.; Sang J. A new weighted mean temperature model in China. Advances in Space Research, 2018, 61(1), 402-412.

Liu Z.; Wong M S.; Nichol J.; et al. A multi-sensor study of water vapour from radiosonde, MODIS and AERONET: a case study of Hong Kong. International Journal of Climatology, 2013, 33(1), 109-120.

Perler D.; Geiger A.; Hurter F. 4D GPS water vapor tomography: new parameterized approaches. Journal of Geodesy, 2011, 85(8), 539-550.

Rius A.; Ruffini G.; and Cucurull L.; "Improving the vertical resolution of ionospheric tomography with GPS occultations,” Geophys. Res. Lett. 1997, 24(18), 291-2294.

Rohm W, Bosy J. Local tomography troposphere model over mountains area. Atmospheric Research, 2009, 93(4), 777-783.

Rohm W.; Bosy J. The verification of GNSS tropospheric tomography model in a mountainous area . Advances in Space Research, 2011, 47(10), 1721-1730.

Saastamoinen, J. Atmospheric correction for the troposphere and stratosphere in radio ranging satellites. The use of artificial satellites for geodesy, 1972, 247-251.

Saito K.; Shoji Y.; Origuchi S.; et al. GPS PWV Assimilation with the JMA Nonhydrostatic 4DVAR and Cloud Resolving Ensemble Forecast for the 2008 August Tokyo Metropolitan Area Local Heavy Rainfalls//Data Assimilation for Atmospheric, Oceanic and Hydrologic Applications (Vol. III). Springer, Cham, 2017, 383-404.

Seko H.; Shimada S.; Nakamura H.; et al. Three-dimensional distribution of water vapor estimated from tropospheric delay of GPS data in a mesoscale precipitation system of the Baiu front [J]. Earth, planets and space, 2000, 52(11), 927-933.

Skone S.; Hoyle V. Troposphere Modeling in a Regional GPS Network. Positioning, 2005, 4(1\&2), 230-239.

Troller M.; Geiger A.; Brockmann E.; et al. Determination of the spatial and temporal variation of tropospheric water vapour using CGPS networks. Geophysical Journal International, 2006, 167(2), 509-520.

Troller M.; B urki B.; Cocard M.; Geiger A.; et al. 3-D refractivity field from GPS double difference tomography. Geophysical Research. Letters, 2002, 29, 2149-2152.

Wang, X., Wang, X., Dai, Z., et al. Tropospheric wet refractivity tomography based on the BeiDou satellite system. Advances in Atmospheric Sciences, 2014, 31(2), 355-362.

Yao Y B.; Zhu S.; Yue S Q. A globally applicable, season-specific model for estimating the weighted mean temperature of the atmosphere. Journal of Geodesy, 2012, 86(12), 1125-1135.

Yao Y B.; Zhao Q Z.; Zhang B. A method to improve the utilization of GNSS observation for water vapor tomography. Annales Geophysicae (09927689), 2016, 34(1), 143-152. 
Ann. Geophys. Discuss., https://doi.org/10.5194/angeo-2018-76

Manuscript under review for journal Ann. Geophys.

Discussion started: 23 July 2018

(c) Author(s) 2018. CC BY 4.0 License.

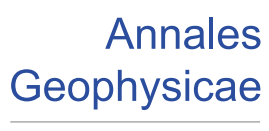

Discussions

(c) (i)

551 Yao Y.; Zhao Q. Maximally Using GPS Observation for Water Vapor Tomography. IEEE Transactions on

552 Geoscience and Remote Sensing, 2016, 54(12), 7185-7196.

553 Yao Y.; Zhao Q. A novel, optimized approach of voxel division for water vapor tomography[J]. Meteorology and

554 Atmospheric Physics, 2017, 129(1), 57-70.

555 Yao Y.; Shan L.; Zhao Q. Establishing a method of short-term rainfall forecasting based on GNSS-derived PWV

556 and its application. Scientific reports, 2017, 7(1), 12465.

557 Yao Y.; Zhang B.; Xu C. and Yan, F. Improved one/multi-parameter models that consider seasonal and geographic

558 variations for estimating weighted mean temperature in ground-based GPS meteorology. Journal of Geodesy, 2014,

559 88(3), 273-282.

560 Yao Y B.; Liu J H.; Zhang B.; et al. Nonlinear relationships between the surface temperature and the weighted

561 mean temperature. Geomatics \& Information Science of Wuhan University, 2015, 40(1), 112-116.

562 Zhang K.; Manning T.; Wu S.; et al. Capturing the signature of severe weather events in Australia using GPS

563 measurements. IEEE Journal of Selected Topics in Applied Earth Observations and Remote Sensing, 2015, 8(4),

564 1839-1847.

565 Zhao Q.; Yao Y. An improved troposphere tomographic approach considering the signals coming from the side

566 face of the tomographic area//Annales Geophysicae. Copernicus GmbH, 2017b, 35(1), 87-95.

567 Zhao Q.; Yao Y.; Cao X.; et al. Accuracy and reliability of tropospheric wet refractivity tomography with GPS,

568 BDS, and GLONASS observations. Advances in Space Research, 2018c. DOI:10.1016/j.asr.2018.01.021

569 Zhao Q.; Yao Y.; Yao W. A troposphere tomography method considering the weighting of input

570 information[C]//Annales Geophysicae. Copernicus GmbH, 2017a, 35(6), 1327-1340.

571 Zhao Q.; Yao Y.; Yao W. GPS-based PWV for precipitation forecasting and its application to a typhoon event.

572 Journal of Atmospheric and Solar-Terrestrial Physics, 2018a, 167, 124-133.

573 Zhao Q.; Yao Y.; Cao X.; et al. An Optimal Tropospheric Tomography Method Based on the Multi-GNSS

574 Observations. Remote Sensing, 2018d, 10(2), 234.

575 Zhao Q.; Yao Y.; Yao W.; et al. Real-time precise point positioning-based zenith tropospheric delay for

576 precipitation forecasting. Scientific reports, 2018b, 8(1), 7939-7939. 